\title{
Pirinç paketleme işinde çalışanların çalışma koşullarının ergonomik risk analizleri ile geliştirilmesi
}

\author{
Melda SEVIMLí ${ }^{1}$, Hilal ATICI ULUSU ${ }^{2}$, Tülin GÜNDÜZ ${ }^{2, *}$ \\ ${ }^{1}$ Işık Üniversitesi İş Sağlığı ve Güvenliği Yüksek Lisans Programı, İstanbul. \\ ${ }^{2}$ Uludağ Üniversitesi Mühendislik Fakültesi Endüstri Mühendisliği Bölümü, Bursa. \\ Gelis Tarihi (Recived Date): 21.06.2017 \\ Kabul Tarihi (Accepted Date): 13.11.2017
}

\section{Özet}

$\mathrm{Bu}$ çalışmada bir çeltik fabrikasındaki üretim hatlarından biri olan paketleme bölümündeki çalışanların ergonomik açıdan risk analizi yapılmış, REBA ve BAUA yöntemlerine göre de ğerlendirilmiştir. REBA ve BAUA yöntemleri işle ilgili kas iskelet bozuklukları risk durumunu ergonomik ve pahalı ekipmanlara ihtiyaç duymadan kolayca değerlendirmek için bir araç olarak önerilmiştir. Bu çalışmada ambalaj toplarının paletten alınması, topların paketleme makinasına götürülmesi, topun paketleme makinasina takılması, paketlerin kolilenmesi, kolilerin paletlenmesi ve paletlerin depoya yerleştirilmesi olmak üzere 6 adet iş istasyonunda çalışan kadın ve erkeklerin ergonomik analizleri yapılmıştır. Ayrıntılı olarak incelenen iş istasyonlarında gerekli öneriler yönetime sunularak önlemler alınmıştır. İyileştirme önerileri duruş bozuklukları ile ilgili eğitim ve ardından takibi yapılarak düzeltilmesi, iş yükü fazla olan istasyonlara bir çallşan eklenmesi ve rotasyon şeklinde çalışılması ve döner tepsi yüksekliğinin ayarlanması olarak uygulanmış ve ergonomik riskler azaltılmıştır.

Anahtar kelimeler: Ergonomi, çalışma koşulları, ergonomik risk analizi, REBA, BAUA.

\footnotetext{
* Tülin GÜNDÜZ, tg@uludag.edu.tr, http://orcid.org/0000-0002-7134-3997

Melda SEVIMLİ, meldasen@ gmail.com, http://orcid.org/0000-0003-2044-0065

Hilal ATICI ULUSU, hilalatici@uludag.edu.tr, http://orcid.org/0000-0001-8347-0806
} 


\title{
Improving working conditions of employees at rice packaging with ergonomic risk analysis
}

\begin{abstract}
In this study, the risk analysis of the employees under the packaging department which is one of the production lines in a paddy factory has been ergonomically performed and they have been evaluated according to the methods of REBA and BAUA. REBA and BAUA methods have been proposed as a tool for assessing easily the risk status of work-related musculoskeletal disorders without the need for ergonomic and expensive equipment. In this study, the ergonomic analysis of the working men and women have been made under six workstation including taking the packaging balls from the palette, carrying the balls into the packaging machine, fitting into the packaging machine, packing the packages and placing the packages into storage. The measures have been taken in the workstations examined in detail, by presenting the necessary proposals to the management. These suggestions for improvements are the correction of the postural disorders with training and then follow-up, the adding of one more employee to the stations with too much workload and the adjustment of the height of the turntable, by providing them, ergonomics risks have been reduced.
\end{abstract}

Keywords: Ergonomics, working conditions, ergonomic risk analysis, REBA, BAUA.

\section{Giriş}

Birçok üretim sürecinde insan gücüne olan ihtiyaç azalmış olmasına rağmen bazı üretim sistemlerinde halen emek yoğun bir çalışma mevcuttur [1]. Gelişen teknoloji ve üretim sistemlerine rağmen yük kaldırma ve yük taşıma, işletmelerde halen çalışan sağlığı için risk oluşturmaya devam etmektedir. Üretimde esnekliğin artması ile birlikte farklı antropometrik yapıdaki çalıșanlar da bu konuda çözüm üretilmesini sınırlandırmaktadır [2]. Çalışma ortamlarının düzenlenmesi hem işçilerin sağlı̆̆ açısından hem de işten verim elde edilmesi açısından oldukça önemlidir. Dolayısıyla ergonomik düzenlemelerin yapılması hem çalışanın rahat bir şekilde iş görmesi hem de firmaların üretim adetlerini arttırması açısından faydalıdır [3].

Günümüzde gıda sektöründe hububat büyük bir paya sahiptir. Hububat sektöründe silolar kullanılsa da hala geleneksel metotlar yani hammaddeyi çuvallayarak depolarda istiflemek şeklinde sürdürülmektedir. Çuvallama, depolama, çuvalları indirme faaliyetlerinin tümü elle taşıma kapsamı içerisindedir. Elle taşıma işi; bir veya daha fazla çalışanın bir yükü kaldırması, indirmesi, itmesi, çekmesi, taşıması veya hareket ettirmesi gibi işler esnasında işin niteliği veya uygun olmayan ergonomik koşullar nedeniyle özellikle bel veya sırtının incinmesiyle sonuçlanabilecek riskleri kapsayan nakletme veya destekleme işlerini ifade eder [4]. Çeltik fabrikası faaliyetleri emek yoğun faaliyetler olduğundan çalışanlarda kas iskelet sitemi rahatsızlıkları sıklıkla görülmektedir.

Çalışma ortamlarında aşırı yük kaldırma ve uygunsuz çalışma pozisyonları gibi fiziksel etkenlere maruz kalındığında, çalışanlarda işe bağlı kas iskelet sistemi rahatsızlıkları gerekli ergonomik düzeltmeler yapılmadığı takdirde artacaktır. Elle Taşıma İşleri 
Yönetmeliği Madde 5'e göre işveren “İşyerinde yüklerin elle taşınmasına gerek duyulmayacak şekilde iş organizasyonu yapmak ve yükün uygun yöntemlerle, özellikle mekanik sistemler kullanılarak taşınmasını sağlamak için gerekli tedbirleri almakla yükümlüdür. Yükün elle taşınmasının kaçınılmaz olduğu durumlarda, elle taşımadan kaynaklanan riskleri azaltmak için uygun yöntemler kullanılmasını sağlamak ve gerekli düzenlemeleri yapmakla yükümlüdür [4].

Dar pencereden bakıldığında çalışma ortamının ergonomik açıdan iyileştirilmesi işveren tarafından gereksiz ve maliyetli olarak görülmektedir. Ancak çerçeve genişletildiğinde iş kazası, yaralanma ve sakatlanmalara bağlı iş gücü kaybı, bedene verilen zararlardan dolayı verilmesi gereken tazminat ve ișçinin tedavisi için yapılan masraflar buzdağının görünmeyen kısmında ortaya çıkarmaktadır. Bu nedenle her zaman "önlemek, ödemekten ucuzdur".

$\mathrm{Bu}$ çalışmada çeltik fabrikası üretim hatlarından biri olan pirinç paketleme bandı incelenmiştir. Paketleme hattındaki iş istasyonları gözlenmiş ve çalışma alanı, çalışanlar tarafından gerçekleştirilen işler, bu sırada maruz kalınan çalışma duruşları incelenerek kaydedilmiştir. Hattın iş akışı çıkarılarak, yapılan işler altı iş istasyonuna ayrılmıştır. Her bir iş için hangi risk değerlendirme yönteminin kullanılacağı belirlenmiş ve yöntemler uygulanmıştır. Pirinç paketlemede uygulanan başlıca faaliyetler ambalaj toplarının paletten alınması, topun makinaya götürülmesi, topun makinaya takılması, çeşitli ağırlıklardaki kolilerin paketlenmesi, kolilerin paletlere dizimi ve son olarak paletlerin depo içerisine yerleştirilme işlemidir. Bu çalışmada pirinç paketleme işinde çalışanların çalışma duruşları için REBA (Hızlı Tüm Vücut Değerlendirme) ve BAUA (Federal Almanya İş Güvenliği ve İş Hekimliği Kurumunun Değerlendirme Yöntemi) yöntemleri kullanılarak risk düzeyleri belirlenmiştir.

\section{Ergonomik risk değerlendirme}

Çalışma ortamlarında ortaya çıkan bazı risk faktörleri, çalışanlarda kas iskelet sistemi rahatsızlıklarına sebep olabilmektedir. Bu rahatsızların önlenebilmesi için öncelikle söz konusu risk faktörlerine nasıl ve ne derecede maruz kalındığı belirlenmeli ve sonrasında tehlike yaratan durumların önüne geçilmelidir. Risklerin değerlendirilmesi için gözleme dayalı yöntemler sıklıkla kullanılmaktadır.

\subsection{REBA yöntemi}

REBA yöntemi, Hignett ve McAtamney tarafından 1999 yılında tasarlanmıştır. REBA tüm vücudun işle ilgili bozukluklarını ve risklerini tahmin etmek için kullanılabilecek bir yöntemdir ve başta sağlık sektörü olmak üzere diğer hizmet sektörlerinde var olan öngörülemeyen çalışma duruşu türlerine duyarlı olacak şekilde geliştirilmiştir [5]. REBA yönteminin en önemli avantajları, gözlemcinin yönteme ilişkin fazladan bilgisinin olmasının gerekmemesi ve kolaylıkla uygulanabilmesidir. Dezavantajları ise farklı işlerde yapılan uygulamalar için ideal gözlem süresi ve gözlem aralıklarının belirsiz olmasidir [6].

REBA kullanılarak analiz edilmek istenilen duruş veya hareketin neden olduğu toplam risk sayısal olarak ifade edilebilir. Riski sayısal olarak ifade edebilmek analiz edilen duruştaki özel hareket ve duruşların ayrı ayrı meydana getirecekleri risk ve tehlikeli durumları belirtmeye yarar. Belirtilen her bir hareket veya duruş üst ve alt vücut için 
açılara ayrılmıştır. Toplam skor boyun, gövde ve alt ve üst uzuvların pozisyonlarının kombinasyonu ile hesaplanır. REBA yöntemindeki diğer faktörler, kaldırılacak yükün kolaylık derecesi, yük üzerindeki kavrama şekli, hareketin ne sıklıkta yapıldığı, hareket sırasında vücudun sabit durması veya hareket ettiğinde aynı zamanda dönme, bükülme olup olmadığıdır [7].

REBA yöntemi ağır ve tehlikeleri işlerde [7], yük kaldırma işlemlerinde [2], üretim ve montaj hatlarındaki çeşitli iş istasyonlarında [1,3] çalışanların çalışma duruşlarının analizi için yaygın olarak kullanılmaktadır.

REBA yönteminin uygulama adımlarının takip edilebileceği REBA kullanıcı formu Ek1 'de verilmiştir. Bu yöntemde çalışma duruşu, vücut bölümlerine ayrı ayrı verilen puanlar ile değerlendirilir. Öncelikle Grup A, gövde, boyun ve bacaklardaki eklem açılarına göre; sonrasında Grup B, üst kol, alt kol ve bileklerdeki eklem açılarına göre puanlanmaktadır. Bu puanlardan tek bir puan elde etmek için Ek-2'de verilen A ve B tabloları kullanılır. A tablosundan elde edilen puana yük/kuvvet puanı eklenerek puan A elde edilir. Puan B'yi elde etmek için de B tablosundan elde edilen puana kavrama puanı eklenir. Puan A ve puan B, Ek-2'deki C tablosunda birleştirildiğinde puan C elde edilmektedir. Son olarak uygulanan kas faaliyetinin tipini temsil eden faaliyet puanı, puan C'ye eklenerek REBA puanı elde edilmektedir. REBA puanına göre eylem seviyeleri belirlenir ve denk geldiği aralığa karşılık gelen önem seviyesinde kontrol önlemleri geliştirilir.

\subsection{BAUA yöntemi}

BAUA yöntemi elle yapılan taşıma ve yerleştirme işleri [8] veya çeşitli yük kaldırma ve yer değiştirme işlemleri [9] için kullanılmaktadır.

\subsubsection{Kaldırma, tutma ve taşıma işlemlerinde risk faktörünün işin temel özelliklerine göre belirlenmesi}

BAUA yöntemine göre ilk adımda zaman ağırlığının belirlenmesi gerekmektedir. Buna göre öncelikle yapılan işin kaldırma-yer değiştirme, tutma ya da taşıma işlerinden hangisi olduğuna karar vermek gerekmektedir. Örneğin koli içine ürün yerleştiriliyorsa, çuval istifleniyorsa, kaldırma-yer değiştirme; matkapla duvar deliniyorsa, taşlama makinası kullanılıyorsa tutma ve bir noktadan diğer noktaya eşya taşınıyorsa da taşıma kategorisine göre değerlendirme yapılır. Zaman ağırlığının belirlenmesinde kaldırmayer değiştirmede günlük yapılan iş sayısı, tutmada bir günde işi yaparken tutma süresi ve taşımada işi yaparken yol alınan mesafe zaman ağırlığını belirlemektedir. İş bir yükü tutmak şeklindeyse toplam tutma süresi Denklem 1 ile bulunur.

Toplam Süre = Tutma hareketi sayısı*Bir tutuşun süresi

Yükün taşınmasının ağırlıklı olduğu işlerde bir günde toplam mesafe olarak yük ile kat edilen yol dikkate alınır. Zaman ağırlığını belirlemede kullanılan değerler Ek-3 Tablo 3a'da verilmiştir.

İkinci adımda yük önemliliği, tutma şekli ve uygulama şartları belirlenmektedir. Yük önemliliğinde işi yapan kişinin cinsiyeti önemlidir. Erkek ve kadın için yük önemliliği ayrı hesaplanır. İş esnasında aynı ağırlıktaki yükler kaldırılmıyorsa kaldırılan yüklerin ortalaması alınmalıdır. Yük önemliliği belirleme tablosu Ek-3 Tablo 3-b'de verilmiştir. 
Konum ağırlığını belirlemek için yükün bedene göre konumu, gövdeden uzak ya da gövdeye yakın olması yükü alırken eğilmek veya uzanmak önemlidir. Ek-3 Tablo 3c'de konum ağırlığı belirleme tablosu verilmiştir. Aradaki değerler için interpolasyon yapilabilir.

Uygulama koşullarında işin yapıldığı ortam önemlidir. Zemin, aydınlatma, tavan yüksekliği, yükün ağırlık merkezinin değişkenliği gibi durumlar etkilidir. Uygulama koşulları belirleme tablosu Ek-3 Tablo 3-d'de verilmiştir.

Son olarak değerlendirme adımında, önceki adımda bulunan yük önemliliği, yükün beden konumuna göre belirlenen konum ağırlığı ve çalışma ortam koşullarının aldığı değerler toplanarak zaman ağırlığı ile çarpılır ve risk faktörü değeri hesaplanır (Denklem 2).

Risk Faktörü = (Yük Önemliliğ $i+$ Konum Ağırllğ $l+$ Uygulama Şartları $)^{*} Z a m a n$ Ağırlı̆̆ $l$

Risk faktörü değeri, Tablo 1'de verilen risk derecelendirme tablosuna göre değerlendirilir ve hangi risk bölgesinde olduğu bulunur [10].

Tablo 1. Risk derecelendirme tablosu.

\begin{tabular}{|c|l|l|}
\hline $\begin{array}{c}\text { Risk } \\
\text { Bölgesi }\end{array}$ & $\begin{array}{l}\text { Risk Faktörü } \\
\text { Değeri }\end{array}$ & Açıklama \\
\hline 1 & $<10$ & $\begin{array}{l}\text { Düşük Yük; vücudun fazla yüklenmesi nedeniyle sağlı̆̆n } \\
\text { kaybedilmesi olası değil. }\end{array}$ \\
\hline 2 & $10<\ldots<25$ & $\begin{array}{l}\text { Biraz Fazla Yük; Az yüklenebilen personel için vücudun fazla } \\
\text { zorlanması olası. Böyle personel için iş düzenlemesinde iyileştirme } \\
\text { anlamlı olur. }\end{array}$ \\
\hline 3 & $25<\ldots<50$ & $\begin{array}{l}\text { Epey Fazla Yük; Normal yüklenebilir kişiler için de vücudun fazla } \\
\text { zorlanması olası. İş düzenlemesi iyileştirme yönüne gidilmeli. }\end{array}$ \\
\hline 4 & $>50$ & $\begin{array}{l}\text { Çok Fazla Yük; Vücudun fazla zorlanma yüklenme olasıllığı çok } \\
\text { yüksek. İş düzenlemesinde iyileştirme önlemleri almak şart. }\end{array}$ \\
\hline
\end{tabular}

$\mathrm{Bu}$ değerlendirme yönteminin temelini bedenin öne eğilme durumu, yükün büyüklüğü, süresi, tekrar sıklığı ve yana dönme veya eğilmenin olup olmadığına göre omurganın zorlanmasının arttığı bilgisi olușturur. Art arda farklı ișler yapılıyorsa bunları ortaklașa değerlendirmek pek kolay ve doğru değildir. Böyle durumlarda risk değerlendirmesi yapabilmek için işin daha detaylı analizi gerekir. Bu çekincelere rağmen bu yöntemle işçinin zorlanmasını artıran faktörlerin kolayca görülmesini sağladığı için bu yöntemin sonuçlarına göre iş düzenlemesinde iyileştirmeye gidilmesinin gerekli olup olmadığ 1 , gerekliyse hangi alanda değişiklik yapmanın daha iyi sonuç vereceği kolayca görülebilir.

\subsubsection{Yük çekme - itme işlemlerinde risk faktörünün işin temel özelliklerine göre belirlenmesi}

İtme ve çekme işlerinde zaman ağırlığını belirlerken dikkat edilecek nokta iş yaparken bir seferde alınan mesafedir. Ek-4 Tablo 4-a'da verilen zaman ağırlığı belirleme tablosunda, 5 metreden küçük ve sık sık durarak yapılan işler ile 5 metreden büyük uzun mesafelerde farklı değerler kullanılmaktadır. 
İkinci adımda yükü taşırken kullanılan yardımcı araçlar belirlenmelidir. Yardımcı araçlar ve uygun katsayılar Ek-4 Tablo 4-b'de verilmiştir. Yük kaydırılarak, yuvarlanarak, el arabası, tekerlekli sehpa, transpalet veya manipülatör kullanılarak taşınabilir. Öncelikle hangi araç kullanıldığı seçildikten sonra yükün ağırlığına göre tabloda uygun katsayı seçilir. Eğer farklı ağırlıklarda itme çekme yapılacaksa taşınan yüklerin ağırlıklarının ortalaması alınmalıdır. Taşınan kütleler arasında bir grup diğerlerinden çok büyükse o grubun taşıma sayısına göre değerlendirme yapılmalıdır. Tabloda 4 ve 5 puanla değerlendirilen alanlar kritik bölgelerdir, boş alanlar ise çalışanın güç sınırını aşma olasılığı yüksek olan alanlardır.

İkinci adımda diğer belirleyici faktör hareket hızıdır. Hareket hızında "hızlı", normal yürüyüş hızıdır. Daha hızlı taşıma işlerinde hıza göre 4 veya 8 puanlı yeni değerlendirme satırı eklenebilir. Burada da gerektiğinde interpolasyona gidilebilir (Ek-4 Tablo 4-c).

Beden konumu için ise Ek-4 Tablo 4-d'de belirtilen konumlara göre değerlendirme yapılır, farklı konumlarda çalışıldığında interpolasyon yapılabilir. Uygulama şartlarında ise en çok tekrarlayan işlemin şartlarına bakılır. İş güvenliğini etkilemeyen iş konforunu azaltacak etkenler dikkate alınmaz.

Sonuç değerlendirmesinde kadınların erkeklere göre performanslarının yaklaşık 2/3 olduğu varsayımından hareketle, kadın çalışanlar için sonuç 1,3 faktörüyle çarpılmalıdır (Denklem 3).

Risk Faktörü $=(\text { Yardımcı Araç }+ \text { Hareket Hızı }+ \text { Beden Konumu })^{*}$ Zaman Ă̆ırlı̆̆ı*1,3 (kadınlar için) $(3)$

Risk faktörü değeri Tablo 1'e göre değerlendirilir ve bulunan risk değerine göre aksiyon alınır [10].

\section{Materyal ve metot}

$\mathrm{Bu}$ çalışmada özel bir işletmede Şubat-Mayıs ayları arasında pirinç paketleme ünitesinde çalışanlar dikkate alınmıştır. Böylece paketleme alanında faaliyet gösteren 5 üretim çalışanı gözlenmiş ve kayıt altına alınmıştır.

Pirinç paketleme işlemlerinde genellikle tüm vücut kullanılarak ve manuel olarak yük kaldırma, taşıma ve yerleştirme işlemleri gerçekleştirilmektedir. $\mathrm{Bu}$ sebeple pirinç paketlemede çalışanların duruşları; tüm vücut değerlendirmesine olanak sağlayan REBA (Hızlı Tüm Vücut Değerlendirme) yöntemi ve kaldırma, tutma, taşıma ve yük çekme-itme durumları için ayrı ayrı detaylı bir analiz yapılmasını sağlayan BAUA (Federal Almanya İș Güvenliği ve İş Hekimliği Kurumu) değerlendirme yöntemi kullanılarak analiz edilmiştir.

\section{Bulgular}

\subsection{Ambalaj topunun paletten alınmast}

Paketleme, çeşitli boyutlardaki ambalaj toplarının paletlerden indirilmesiyle başlamaktadır. Farklı ağırlıklardaki ambalaj toplarının paletten indirilmesi sırasında 
oluşan risk faktörü BAUA yöntemine göre hesaplanmıştır. Yük tutma süresi dikkate alınarak zaman ağırlığı 1 olarak belirlenmiştir. Çalışanın yük kaldırma pozisyonu ve elde edilen risk seviyeleri Tablo 2'de verilmiştir.

Değerlendirme aşamasında bulunan değer 28'dir. 25-50 arasında bir değer olduğu için risk seviyesi 3 olarak bulunmuştur. Risk değerlendirme tablosuna göre Epey Fazla Yük yani normal yüklenebilir kişiler için de vücudun fazla zorlanması olasıdır. İş düzenlemesi iyileştirme yönüne gidilmelidir. Ambalaj topunu iki kadın çalışanın kaldırması durumunda kişi başına düşen yük miktarı yarı yarıya azalacaktır. Buna göre 20,30 ve $40 \mathrm{~kg}$ ağırlığındaki yükler için risk seviyesi bir kademe düşürülebilmektedir ancak $50 \mathrm{~kg}$ ağırlığındaki ambalaj topu için risk seviyesi düşmemektedir. Ambalaj topunu iki erkek çalışanın kaldırması durumunda risk seviyesi 20 ve $30 \mathrm{~kg}$ 'lık yüklerde düşürülebilir ancak 40 ve 50 kg'lık yüklerde düşmemektedir.

Tablo 2. Ambalaj toplarının paletten indirilmesi sırasındaki risk seviyeleri.

\begin{tabular}{|c|c|c|c|c|c|c|c|}
\hline \multirow{2}{*}{ 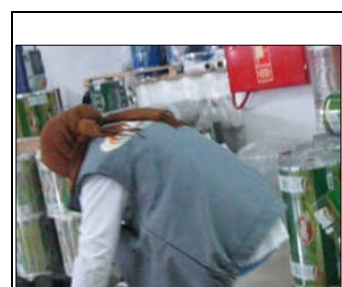 } & \multirow[b]{2}{*}{ 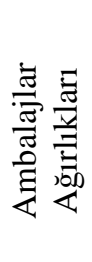 } & \multirow{2}{*}{$\begin{array}{l}\text { 1.Adım } \\
\text { Zaman } \\
\text { Ağırlığ1 }\end{array}$} & \multicolumn{3}{|c|}{ 2.Adım } & \multirow{2}{*}{$\begin{array}{c}\text { 3. Adım } \\
\text { Değerlendirme }\end{array}$} & \multirow[b]{2}{*}{ Risk Seviyesi } \\
\hline & & & 兰: & 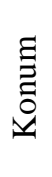 & 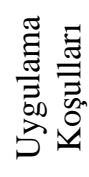 & & \\
\hline & $50 \mathrm{~kg}$ & 1 & 25 & 3 & 0 & $(25+3+0) \times 1=28$ & 3 Epey Fazla Yük \\
\hline-5 & $40 \mathrm{~kg}$ & 1 & 25 & 3 & 0 & $(25+3+0) \times 1=28$ & 3 Epey Fazla Yük \\
\hline & $30 \mathrm{~kg}$ & 1 & 25 & 3 & 0 & $(25+3+0) \times 1=28$ & 3 Epey Fazla Yük \\
\hline & $20 \mathrm{~kg}$ & 1 & 7 & 3 & 0 & $(7+3+0) \times 1=10$ & 2 Biraz Fazla Yük \\
\hline
\end{tabular}

\subsection{Ambalaj topunun makinaya götürïlmesi}

Paketleme sürecinin ikinci aşamasında paletlerden indirilen ambalaj topları araç kullanmadan paketleme makinasının yanına götürülmektedir. Bu işlemdeki risk faktörü, yapılan işin çekme-itme işi olmasından dolayı BAUA yöntemi kullanılarak hesaplanmıştır.

Bir günde ortalama 25-30 ton pirinç paketlenmektedir. Buna göre 50 kg'lik ambalaj ile 1-1,5 top, $40 \mathrm{~kg}$ 'llk ambalaj ile 2 top, 30 ve $20 \mathrm{~kg}$ 'llk ambalaj ile 4 top malzeme kullanılmaktadır. Bir günde yapılan iş sayısı 10' dan az olduğundan zaman ağırlığı 1 olarak seçilmiştir. Ambalaj topları herhangi bir yardımcı araç kullanılmadan makinaya yuvarlanarak götürüldüğünden iş şartlarının ağırlığı 1 olarak seçilmiştir. Normal yürüme hızlı olarak kabul edildiğinden, ambalaj topunun yuvarlanarak yürünmesi yürüme hızından yavaş olacağı için hareket hızı yavaş olarak seçilmiştir. Üst gövde öne eğik olduğundan beden konumu ağırlık derecesi ise 2 olarak seçilmiştir. Buna göre risk değeri 5,2 olarak hesaplanmıştır. Farklı ağırlıktaki ambalaj topları için de aynı iş aynı yöntemle değerlendirildiğinde elde edilen sonuçlar Tablo 3'de verilmiştir.

Risk faktörü, 10'dan az olduğundan Düşük Yük yani vücudun fazla yüklenmesi nedeniyle sağlığın kaybedilmesi olası değildir. Yapılan analizlerden de anlaşıldığı gibi yapılan iş sayısının 10'dan fazla olmaması, çalışma ortam şartlarının iyi olması sebebiyle risk seviye 1 olarak bulunmuştur. Bu durumda çalışma ortamında herhangi bir iyileştirme yapılmasına gerek duyulmamaktadır. 
Tablo 3. Ambalaj toplarının makinaya götürülmesi sırasındaki risk seviyeleri.

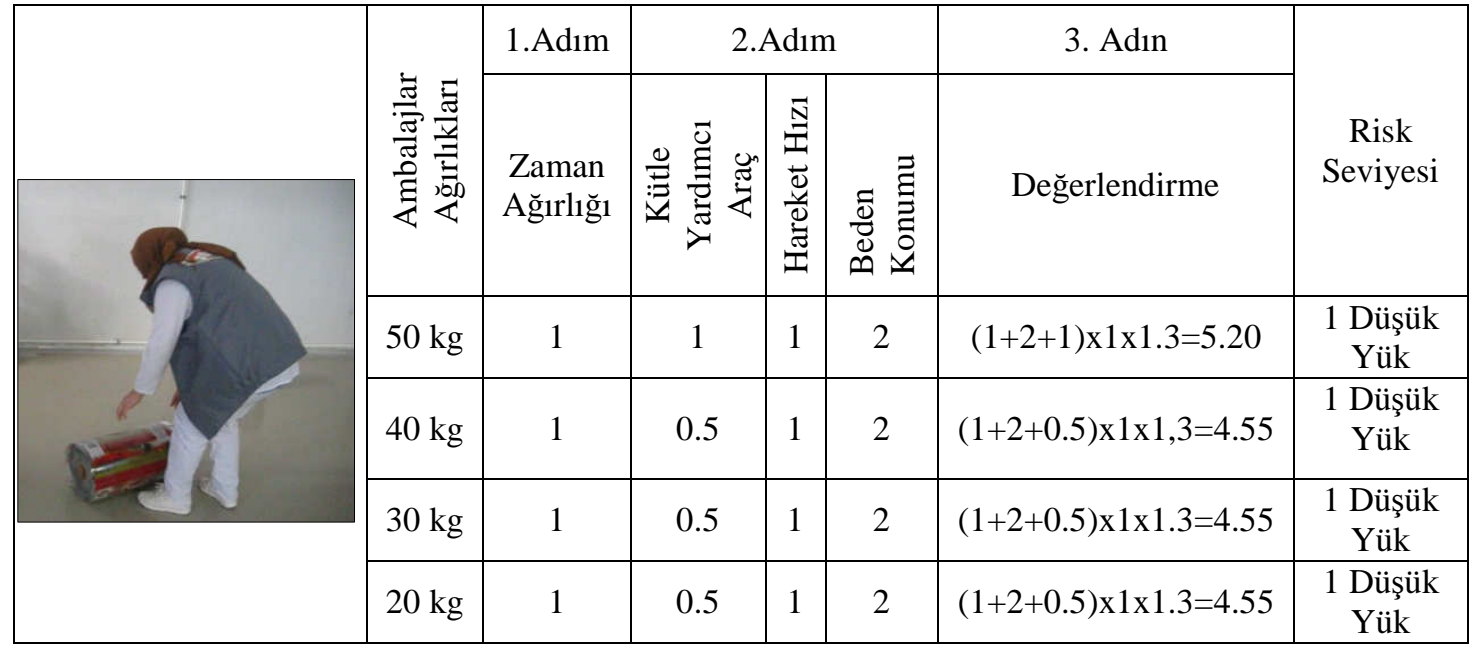

\subsection{Ambalaj topunun makinaya takılması}

Topun makinaya takılması sırasındaki iş çoğunlukla el, kol beden ve bacak hareketlerini gerektirdiği için REBA yöntemine göre incelenmiştir. REBA yöntemi ile yapılan değerlendirme Tablo 4'de verilmiştir.

Tablo 4. Ambalaj toplarının makinaya takılması sırasındaki risk seviyesi.

\begin{tabular}{|c|c|c|c|c|c|c|}
\hline \multirow{10}{*}{ 4. } & \multicolumn{6}{|c|}{ Ambalaj topunun makinaya takılması } \\
\hline & \multicolumn{2}{|c|}{ A Grubu } & Tablo & Tablo & \multicolumn{2}{|c|}{ B Grubu } \\
\hline & Gövde & 4 & \multirow{3}{*}{5} & \multirow{3}{*}{3} & 2 & Üst Kol \\
\hline & Boyun & 1 & & & 2 & Alt Kol \\
\hline & Bacaklar & $1+1$ & & & 1 & Bilek \\
\hline & Yük/Kuvvet & & 2 & 0 & & Kavrama \\
\hline & A Skoru & & 7 & 3 & & B Skoru \\
\hline & & C Skoru & & & & \\
\hline & & Aktivite Skoru & & & & \\
\hline & & REBA Skoru & & & & \\
\hline
\end{tabular}

Ambalaj malzemesinin değişimi sırasından eğilirken dizler kullanılmadan bele yüklenilerek hareket edildiğinden dolayı risk seviyesi 3. seviyede bulunmuştur. Ambalaj toplarının insan kullanılmadan değişimi mevcut makinalar için olanaksızdır. Bu nedenle öncelikle risk seviyesini bu şekilde düşürebilmek hedeflenmiştir. Bunun için çalışanlara yük kaldırmayla ilgili eğitim verilmelidir. Çalışanlar ağılığı kaldırdıkları sırada yükün ağırlığı bele değil dizlere binmelidir. Çalışanlara yük kaldırma eğitimi verildikten sonra takibi yapılmıştır. Yük kaldırma şekli alışkanlık haline geldikten sonra ergonomik analizleri yapılmıştır. Yapılan analizde REBA skoru 7 olarak bulunmuştur.

\subsection{Paketlerin kolilenmesi}

Paketleme işleminden sonra paketlerin kolilenmesi işlemi REBA yöntemi ile değerlendirilmiştir. REBA yöntemi ile yapılan değerlendirme Tablo 5'te verilmiştir.

Paketlerin kolilenmesi sırasında yapılan ergonomik analizde risk seviyesi 3. seviyede yani yüksek olarak bulunmuştur. Kısa süre içerisinde iyileştirme yapılması gerekmektedir. Paketlerin düştüğü döner tepsinin yüksekliği arttırılırsa gövdedeki 
eğilme hareketi azalacaktır. Dolayısıyla paketlerin alındığı döner tepsinin ayakları yükseltilmiştir. Böylece paket alınırken öne doğru gövdenin yaptığı bükülme hareketi ortadan kalkmış ve yük iki ayak üzerine binmiştir. Böylece yeniden hesaplanan REBA risk skoru 5 olarak bulunmuştur.

Tablo 5. Paketlerin kolilenmesi sırasındaki risk seviyesi.

\begin{tabular}{|c|c|c|c|c|c|c|}
\hline$\theta$ & \multicolumn{6}{|c|}{ Ambalaj topunun makinaya takılması } \\
\hline & \multicolumn{2}{|c|}{ A Grubu } & Tablo & Tablo & \multicolumn{2}{|c|}{ B Grubu } \\
\hline & Gövde & 4 & \multirow{3}{*}{5} & \multirow{3}{*}{3} & 2 & Üst Kol \\
\hline & Boyun & 1 & & & 2 & Alt Kol \\
\hline & Bacaklar & $1+1$ & & & 1 & Bilek \\
\hline \multirow{5}{*}{$-1=\alpha^{2}$} & Yük/Kuvvet & & 2 & 0 & & Kavrama \\
\hline & A Skoru & & 7 & 3 & & B Skoru \\
\hline & & C Skoru & & 7 & & \\
\hline & & Aktivite Skoru & & 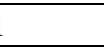 & & \\
\hline & & REBA Skoru & & 3 & & \\
\hline
\end{tabular}

\subsection{Kolilerin palete istiflenmesi}

Paketleme bölümünde $5 \mathrm{~kg}$ 'lık ambalajlardan günlük ortalama 30 ton pirinç paketlenmektedir. İki adet paketleme makinası mevcuttur ve bandın ucunda iki kişi çalışmaktadır. Koliler $20 \mathrm{~kg}$ ağırlığındadır. Buna göre kişi başına 750 koli düşmektedir. $\mathrm{Bu}$ işlem BAUA yöntemi ile değerlendirilmiştir. Kolilerin palet üzerine dizilme işlemi ve farklı ağırlıklardaki koliler için yapılan değerlendirme sonuçları Tablo 6' da verilmiştir.

Tablo 6. Kolilerin palet üzerine dizilmesi sırasındaki risk seviyeleri.

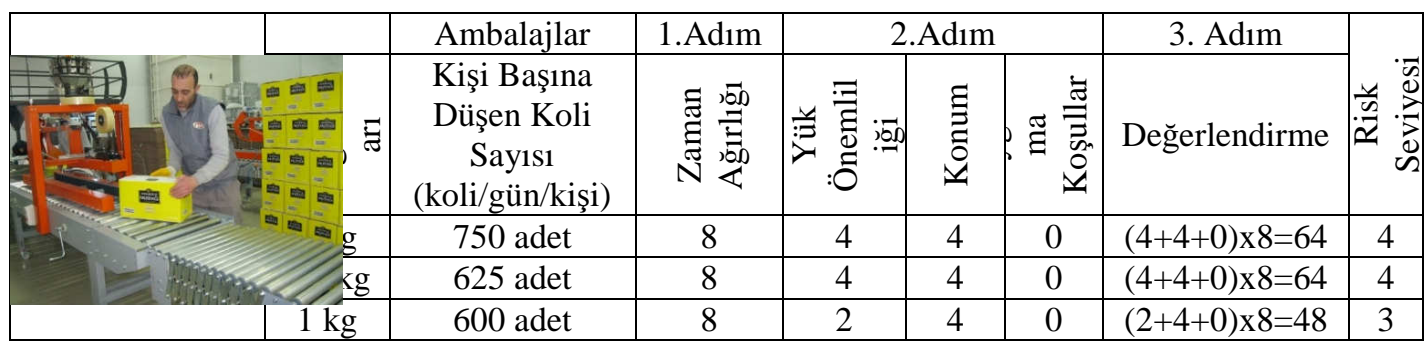

Paketlenen ürünleri kolilere yerleştirme için sadece bir kişi çalıştığında bedene aşırı yük binmektedir. Risk seviyesini düşürmek için iyileştirme yapılmalıdır. Kolilerin paletlere dizilmesi işinde öncelikle çalışanlara yük kaldırmayla ilgili davranışlarını düzeltmeleri için eğitim verilmelidir. Yapılan hesaplamalarda iyileştirmelerde ilk aşama olarak risk seviyesini bir seviye düşürebilmek esastır. Buna göre yapılan iş sırasında aynı işi iki kişi birlikte yaparsa işlem süresi tam olarak yarı yarıya düşmemekle birlikte tekrar sayısı azalacaktır. Bu sayede risk seviyesi düşecek ve uzun vadede çalışan sağlığı olumlu etkilenecektir.

\subsection{Paletlerin depoya yerleștirilmesi}

Kolilerin istiflendiği paletlerin depoya taşınması ve yerleștirilmesi sırasında, bir palet ağırlığ 800 - $1000 \mathrm{~kg}$ arasında olmaktadır. Günlük ortalama 30 palet hazırlanmaktadır ve paletin hazırlandığı nokta ile depolandığı nokta arasındaki mesafe 15 metredir. 
Günlük 30 palet için toplamda $450 \mathrm{~m}$ taşıma yapılmaktadır. Bu işlem BAUA yöntemi ile değerlendirilmiş ve Tablo 7'de görüldüğü gibi risk seviyesi 2 olarak bulunmuştur.

Yapılan değerlendirmeye göre paletlerin depoya yerleştirilmesi işlemi için iyileştirme yapılması gerekmektedir. Paletler üzerindeki yük miktarı ve ortam koşulları değiştirilemediği için paleti transpalet ile depoya yerleştiren çalışan için itme çekme mesafesini düşürmek risk seviyesini 1 seviye düşürmek için etkili olacaktır. Buna göre paletleri yerleştirme işini rotasyon ile iki çalışan yaparsa kişi başına 15 palet için toplamda $225 \mathrm{~m}$ taşıma yapılacaktır. Bu durumda risk seviyesi 1. seviyeye düşürülecektir.

Tablo 7. Paletlerin depoya yerleştirilmesi sırasındaki risk seviyesi

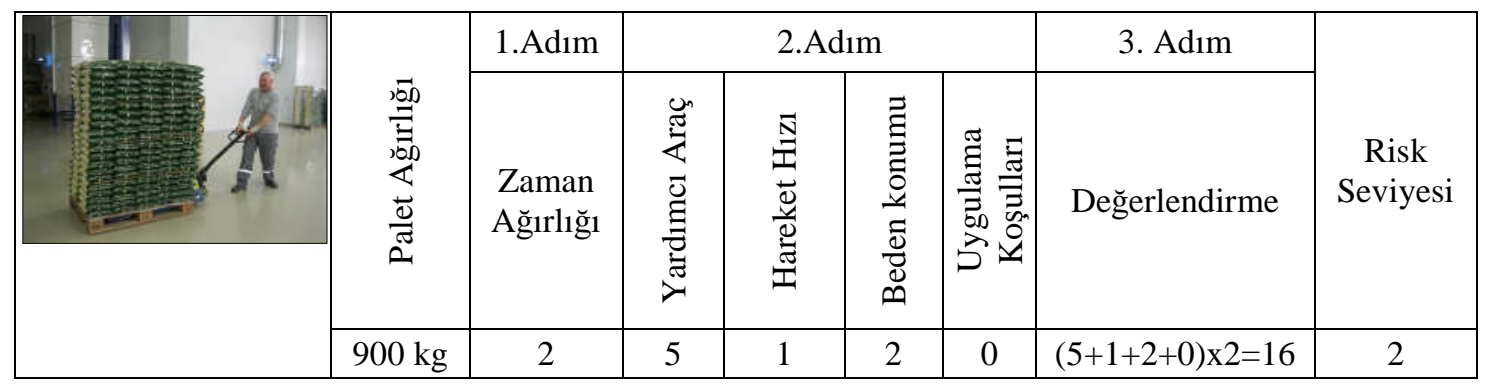

\section{Değerlendirme ve sonuç}

Bu çalışmada pirinç paketleme bandında bulunan altı adet iş istasyonunda yük kaldırma, yük taşıma ve yük itme-çekme işlemleri incelenerek REBA ve BAUA yöntemleriyle analizleri yapılmış ve çalışanların maruz kaldığı risklerin azaltılması hedeflenmiştir.

Altı adet iş istasyonundan ilki olan ambalaj toplarının paletten alınması sırasındaki duruşlar BAUA yöntemine göre değerlendirilmiş, değerlendirme sonunda risk puanı 28 olarak hesaplanmıştır. Bu faaliyet 3. derece risk bölgesinde yer almaktadır. Bulunan risk bölgesine göre iş istasyonunda iş düzenlemesi yönüne gidilmiş ve ambalaj toplarının paletten alınması işini iki erkek çalışan tarafından yapılması önerilmiş ve faaliyete geçirilmiştir. Aynı iş istasyonu düzenlemeden sonra analiz tekrar edilmiş ve risk 1. dereceye düşürülmüştür.

İkinci iş istasyonu olan topun makinaya götürülmesi işi BAUA yöntemine göre analiz edilmiştir. Bu istasyonda yapılan analizlere göre çalışma şartlarının iyi olması, bedenin konumu ve iş tekrar sayısının az olmasından dolayı risk puanı 10'dan küçük olarak hesaplanmıştır. Risk 1. derecede bulunmuş ve iş istasyonunda iyileștirme gerekli bulunmamıștır.

Üçüncü iş istasyonunda ambalaj topunun makinaya takılması ele alınmış ve çalışma sırasındaki vücut duruşları REBA yöntemi ile incelenmiştir. Yapılan analiz sonucunda risk puanı 8 olarak hesaplanmıştır. Bulunan skora göre iyileştirme yapılması gerektiği öngörülmüştür. Çalışanlara yük kaldırma sırasında vücutlarını doğru kullanmalarıyla ilgili eğitim verilmiştir. Eğitim sonucunda çalışanlar izlendiğinde davranış değişikliği gözlemlenmiş ve yükü kaldırırken ağırlığı bel üzerinden değil dizler üzerinden taşınması sağlanmıştır. REBA yöntemine göre analiz tekrarlandığında risk puanının 7’ye düştügü hesaplanmıştır. 
Dördüncü iş istasyonu olan paketlerin kolilenmesi işleminin REBA yöntemi ile analizi yapılmıştır. Yapılan analize göre risk puanı 8 olarak hesaplanmıştır ve iyileştirme yapılması gerekmektedir. Paketlerin alındığı döner tepsinin yerden yüksekliği arttırılmış böylece paketi tepsiden alırken yapılan eğilme hareketi kaldırılmıștır. Risk puanı 5 olarak hesaplanmış risk derecesi yüksek riskten, orta riske düşürülmüştür.

Beşinci iş istasyonu olan ve iki bandın ucunda da birer çalışanın bulunduğu kolilerin paletlere istiflenmesi işleminin ergonomik analizi BAUA yöntemi ile yapılmış ve değerlendirme sonucunda risk puanı 64 olarak hesaplanmıştır. Risk seviyesi 4 olan bu değer, çalışan bedeni için çok fazla yük olduğu anlamına gelmektedir. İyileştirme olarak her bant sonuna iki çalışan yerleştirilmiş dolayısıyla tekrar sayısı düşürülmüştür. Tekrar analiz yapıldığında risk seviyesinin 3'e düştüğü görülmüsstür.

Son istasyon olan paletlerin depoya yerleştirilmesinde BAUA yöntemine göre yapılan analizler sonucunda risk seviyesi 2 olarak hesaplanmıştır. Yapılan iyileștirmede depoya paletlerin yerleştirme işini iki kişi tarafından rotasyon oluşturacak şekilde yapılması sağlanmıştır. Tekrar sayısı ve alınan mesafe azaldığı için yeniden analiz yapılması sonucunda risk seviyesi 1 olarak hesaplanmıştır.

Mevcut durumda çalışanların ergonomik olmayan koşullarda yük kaldırma ve taşıma yaptığı görülmüş hem küçük işyeri düzenlemesi hem de çalışanların çalışma şekillerine ufak müdahaleler ile çalışanın ergonomik koşullarda işlerine devam etmesi sağlanmıştır. Böylece bu çalışmanın işletmelerde çoğunlukla benzer şekilde elle yapılan itme, çekme, taşıma işlemleri için REBA, BAUA gibi uygun yöntemler kullanılarak yapılacak olan ergonomik risk değerlendirme çalışmalarında yardımcı nitelikte olacağı düşünülmektedir. Ayrıca iş yerinde manuel olarak yapılan kaldırma ve taşıma işlerinin birtakım yardımcı düzenekler ile yapılması da mümkündür. Bu sayede çalışanda oluşan risk seviyesinin daha da azaltılması sağlanacaktır.

\section{Kaynaklar}

[1] Atıcı, H., Gönen, D. ve Oral, A., Çalışanlarda zorlanmaya neden olan duruşların REBA yöntemi ile ergonomik analizi, Süleyman Demirel Üniversitesi Mühendislik Bilimleri ve Tasarım Dergisi, 3(3), ÖS:Ergonomi, 239-244, (2015).

[2] Cengiz, T.G. ve Pişkin, K.K., Otomobil koltuğu kılıfı İmalatı yapılan bir firmada RWL, REBA ve RULA yöntemleri kullanılarak yapılan yük kaldırma analizleri, 19. Ulusal Ergonomi Kongresi Bildiriler Kitabı, Balıkesir, (2013).

[3] Sağıroğlu, H., Coşkun, M. B. ve Erginel, N., REBA ile bir üretim hattındaki iş istasyonlarının ergonomik analizi, Süleyman Demirel Üniversitesi Mühendislik Bilimleri ve Tasarım Dergisi, 3(3), ÖS:Ergonomi, 339-345, (2015).

[4] Çalışma ve Sosyal Güvenlik Bakanlığı, Elle taşıma işleri yönetmeliği, (2013). http://mevzuat.basbakanlik.gov.tr/Metin.Aspx?MevzuatKod=7.5.18627\&Mevzu atIliski=0\&sourceXmlSearch=elle, (Haziran 2016).

[5] Hignett, S. ve McAtamney, L., Rapid entire body assessment (REBA), Applied Ergonomics, 31(2), 201-205, (2000). 
[6] Okan, S. Ü. ve Kaya, A., Orman fidanlıklarında fidan replikaj işlerinde çalışma duruşlarının REBA yöntemi ile analizi, Süleyman Demirel Üniversitesi Mühendislik Bilimleri ve Tasarım Dergisi, 3, 157-163, (2015).

[7] Kocabaş, M., Ağır ve tehlikeli işlerde çalışan iş görenlerde zorlanmaya neden olan Çalışma duruşlarının analizi, Yüksek Lisans Tezi, Selçuk Üniversitesi, Fen Bilimleri Enstitüsü, Konya, (2009).

[8] Yetim, H. ve Gündüz, T., Taşıma kaplarının elle yerleştirilmesinde zorlanmaya neden olan çalışma duruşlarının analizi, Press Academia Procedia, Global Business Research Congress (GBRC), 1, (2015).

[9] Alıcı, H. ve Gündüz, T., Vakumlu sistemler ile yük kaldırma ve taşıma işinin insan sağlığına etkisinin değerlendirilmesi,. Press Academia Procedia, Global Business Research Congress (GBRC), 1, (2015).

[10] Babalık, F.C., Mühendisler için ergonomi - işbilim (4. Baskı). Dora Yayıncılık, Bursa, (2014). 


\section{EK - 1 REBA Kullanıcı Formu}

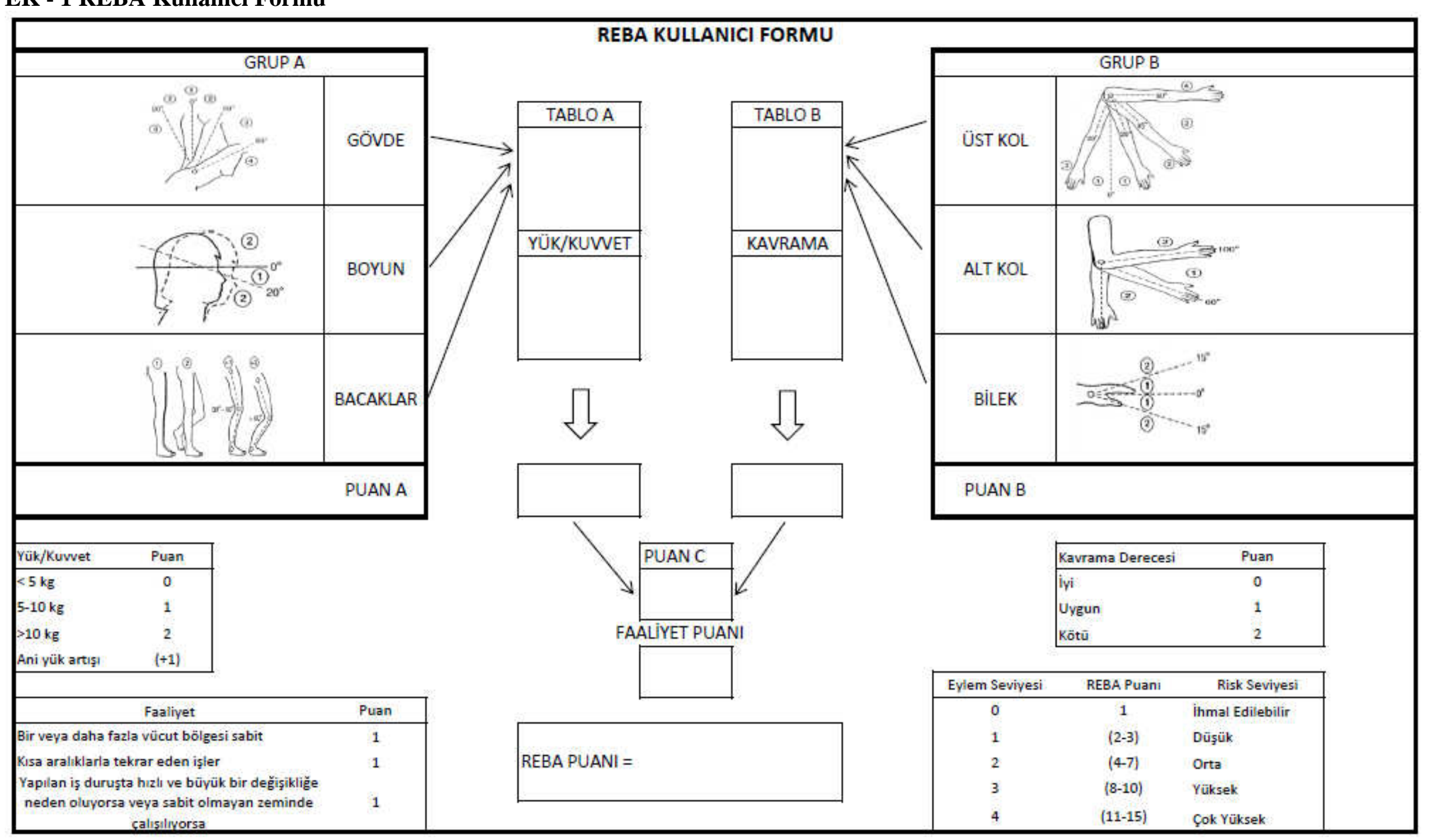




\section{EK - 2 REBA Tabloları}

REBA A Tablosu

\begin{tabular}{|c|c|c|c|c|c|c|c|c|c|c|c|c|c|}
\hline & \multicolumn{12}{|c|}{ BOYUN } \\
\hline & & \multicolumn{4}{|c|}{1} & \multicolumn{4}{|c|}{2} & \multicolumn{4}{|c|}{3} \\
\hline & & \multicolumn{4}{|c|}{ BACAKLAR } & \multicolumn{4}{|c|}{ BACAKLAR } & \multicolumn{4}{|c|}{ BACAKLAR } \\
\hline & & 1 & 2 & 3 & 4 & 1 & 2 & 3 & 4 & 1 & 2 & 3 & 4 \\
\hline \multirow{5}{*}{ 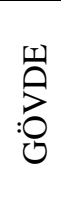 } & 1 & 1 & 2 & 3 & 4 & 1 & 2 & 3 & 4 & 3 & 4 & 5 & 6 \\
\hline & 2 & 2 & 3 & 4 & 5 & 3 & 4 & 5 & 6 & 4 & 5 & 6 & 7 \\
\hline & 3 & 2 & 4 & 5 & 6 & 4 & 5 & 6 & 7 & 5 & 6 & 7 & 8 \\
\hline & 4 & 3 & 5 & 6 & 7 & 5 & 6 & 7 & 8 & 6 & 7 & 8 & 9 \\
\hline & 5 & 4 & 5 & 6 & 7 & 6 & 7 & 8 & 9 & 7 & 8 & 9 & 9 \\
\hline
\end{tabular}

REBA B Tablosu

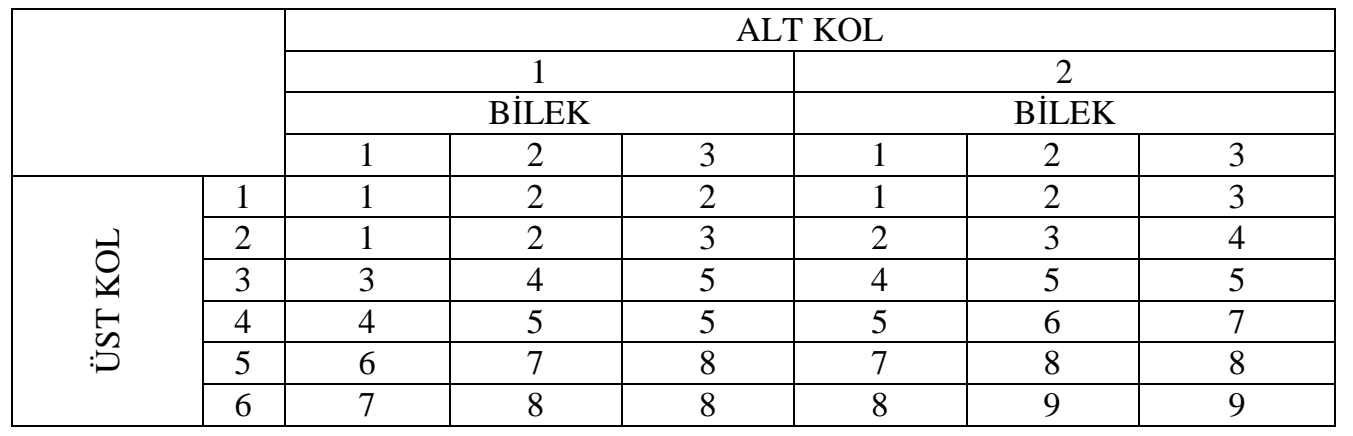

REBA C Tablosu

\begin{tabular}{|c|c|c|c|c|c|c|c|c|c|c|c|c|c|}
\hline & \multicolumn{12}{|c|}{ B PUANI } \\
\hline & & 1 & 2 & 3 & 4 & 5 & 6 & 7 & 8 & 9 & 10 & 11 & 12 \\
\hline \multirow{12}{*}{ 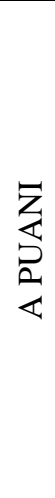 } & 1 & 1 & 1 & 1 & 2 & 3 & 3 & 4 & 5 & 6 & 7 & 7 & 7 \\
\hline & 2 & 1 & 2 & 2 & 3 & 4 & 4 & 5 & 6 & 6 & 7 & 7 & 8 \\
\hline & 3 & 2 & 3 & 3 & 3 & 4 & 5 & 6 & 7 & 7 & 8 & 8 & 8 \\
\hline & 4 & 3 & 4 & 4 & 4 & 5 & 6 & 7 & 8 & 8 & 9 & 9 & 9 \\
\hline & 5 & 4 & 4 & 4 & 5 & 6 & 7 & 8 & 8 & 9 & 9 & 9 & 9 \\
\hline & 6 & 6 & 6 & 6 & 7 & 8 & 8 & 9 & 9 & 10 & 10 & 10 & 10 \\
\hline & 7 & 7 & 7 & 7 & 8 & 9 & 9 & 9 & 10 & 10 & 11 & 11 & 11 \\
\hline & 8 & 8 & 8 & 8 & 9 & 10 & 10 & 10 & 10 & 10 & 11 & 11 & 11 \\
\hline & 9 & 9 & 9 & 9 & 10 & 10 & 10 & 11 & 11 & 11 & 12 & 12 & 12 \\
\hline & 10 & 10 & 10 & 10 & 11 & 11 & 11 & 11 & 12 & 12 & 12 & 12 & 12 \\
\hline & 11 & 11 & 11 & 11 & 11 & 12 & 12 & 12 & 12 & 12 & 12 & 12 & 12 \\
\hline & 12 & 12 & 12 & 12 & 12 & 12 & 12 & 12 & 12 & 12 & 12 & 12 & 12 \\
\hline
\end{tabular}




\section{EK - 3 Yük Kaldırma için BAUA Tabloları}

Tablo 3-a. Zaman A ğırlığı Belirleme

\begin{tabular}{|c|c|c|c|c|c|}
\hline \multicolumn{2}{|c|}{ Kaldırma ve Yer Değiştirme $(<5 s)$} & \multicolumn{2}{|c|}{ Tutma (>5 s) } & \multicolumn{2}{|c|}{ Taşıma (>5 s) } \\
\hline $\begin{array}{c}\text { Bir günde } \\
\text { yapılan iş sayısı }\end{array}$ & $\begin{array}{l}\text { Zaman } \\
\text { ağırlığ1 }\end{array}$ & Bir günde toplam süre & Zaman ağırlığ & $\begin{array}{c}\text { Bir günde } \\
\text { toplam mesafe }\end{array}$ & $\begin{array}{l}\text { Zaman } \\
\text { ağırlığı }\end{array}$ \\
\hline$<10$ & 1 & $>5$ dak & 1 & $<300 \mathrm{~m}$ & 1 \\
\hline $10<\ldots<40$ & 2 & $5<\ldots<15$ dak & 2 & $300 \mathrm{~m}<\ldots<1 \mathrm{~km}$ & 2 \\
\hline $40<\ldots<200$ & 4 & 15 dak $<\ldots<1$ saat & 4 & $1<\ldots<4 \mathrm{~km}$ & 4 \\
\hline $20<\ldots<500$ & 6 & $1<\ldots<2$ saat & 6 & $4<\ldots<8 \mathrm{~km}$ & 6 \\
\hline $500<\ldots<1000$ & 8 & $2<\ldots<4$ saat & 8 & $8<\ldots<16 \mathrm{~km}$ & 8 \\
\hline$\geq 1000$ & 10 & $\geq 4 \mathrm{sa}$ & 10 & $\geq 16 \mathrm{~km}$ & 10 \\
\hline \multicolumn{2}{|c|}{$\begin{array}{c}\text { Örnekler; Duvara tuğla dizme, } \\
\text { makinaya iş parçası yükleme, } \\
\text { konteynerden kutuları alma bir } \\
\text { bant üzerine koyma }\end{array}$} & \multicolumn{2}{|c|}{$\begin{array}{l}\text { Örnekler; Bir taşlama sehpasında } \\
\text { işlemek üzere döküm boruların } \\
\text { tutulması ve sürülmesi, bir elde taşlama } \\
\text { makinasının tutulması, motorlu tırpanın } \\
\text { calıștırılması }\end{array}$} & \multicolumn{2}{|c|}{$\begin{array}{c}\text { Örnekler; Mobilya } \\
\text { nakliyesi, bir kamyondan } \\
\text { iskele parçasının yerlerine } \\
\text { taşınması }\end{array}$} \\
\hline
\end{tabular}

Tablo 3-b. Yük Önemliliği Belirleme

\begin{tabular}{|c|c|c|c|}
\hline Etken Kuvvet (Erkekler İçin) & Yük Önemliliği & Etken Kuvvet (Kadınlar İçin) & Yük Önemliliği \\
\hline$<10 \mathrm{~kg}$ & 1 & $<5 \mathrm{~kg}$ & 1 \\
\hline $10<\ldots<20 \mathrm{~kg}$ & 2 & $5<\ldots<10 \mathrm{~kg}$ & 2 \\
\hline $20<\ldots<30 \mathrm{~kg}$ & 4 & $10<\ldots<15 \mathrm{~kg}$ & 4 \\
\hline $30<\ldots<40 \mathrm{~kg}$ & 7 & $15<\ldots<25 \mathrm{~kg}$ & 7 \\
\hline$\geq 40 \mathrm{~kg}$ & 25 & $\geq 25 \mathrm{~kg}$ & 25 \\
\hline
\end{tabular}

Tablo 3-c. Konum Ağırlığı Belirleme

\begin{tabular}{|c|c|c|}
\hline & Vücut Duruşu, Yükün Pozisyonu & $\begin{array}{c}\text { Konum } \\
\text { Ağırlığı }\end{array}$ \\
\hline & $\begin{array}{c}\text { - Gövdenin üstü dik, Döndürülmüyor } \\
\text { - Yük gövdede }\end{array}$ & 1 \\
\hline \\
\hline
\end{tabular}

Tablo 3-d. Uygulama Koşulları Belirleme

\begin{tabular}{|c|c|}
\hline Uygulama Koşulları & Uygulama Ağırlığ \\
\hline $\begin{array}{l}\text { İyi ergonomik koşullar, örneğin yeterli alan, engelsiz çalışma alanı, düz-kaymayan } \\
\text { zemin, yeterli aydınlatma, tutabilme iyi ve kolay }\end{array}$ & 0 \\
\hline $\begin{array}{l}\text { Hareket etme olanağı sınırlı, ergonomik koşullar kötü. Örnek: } \\
\text { 1.Alçak tavan ve } 1,5 \mathrm{~m}^{2} \text { den daha az çalışma alanı } \\
\text { 2.Düz olmayan veya yumuşak zemin nedeniyle ayakta dururken sendeleme, düşme } \\
\text { olasılığı }\end{array}$ & 1 \\
\hline $\begin{array}{l}\text { Hareket etme serbestliği çok sınırlanmış ve/veya yükün ağırlık merkezinin } \\
\text { değişken olması (örneğin hasta taşıma) }\end{array}$ & 2 \\
\hline
\end{tabular}


EK - 4 Yük Taşıma için BAUA Tabloları

Tablo 4-a. Zaman Ağırlığı Belirleme

\begin{tabular}{|c|c|c|c|}
\hline \multicolumn{2}{|c|}{$\begin{array}{l}\text { Kısa Mesafelerde çekme-itme veya sık sık } \\
\text { durarak çekme-itme (Bir Seferde }<5 \text { m) }\end{array}$} & \multicolumn{2}{|c|}{$\begin{array}{l}\text { Uzun Mesafelerde itme ve çekme (Bir seferde > } 5 \\
\text { metre) }\end{array}$} \\
\hline $\begin{array}{l}\text { Bir Günde Yapılan İş } \\
\text { Sayısı }\end{array}$ & Zaman Ağırlığı & $\begin{array}{c}\text { Bir Günde Toplam } \\
\text { Mesafe }\end{array}$ & Zaman Ağırlığı \\
\hline$<10$ & 1 & $<300 \mathrm{~m}$ & 1 \\
\hline $10<\ldots<40$ & 2 & $300 \mathrm{~m}<\ldots<1 \mathrm{~km}$ & 2 \\
\hline $40<\ldots<200$ & 4 & $1 \mathrm{~km}<\ldots<4 \mathrm{~km}$ & 4 \\
\hline $200<\ldots<500$ & 6 & $4 \mathrm{~km}<\ldots<8 \mathrm{~km}$ & 6 \\
\hline $500<\ldots<1000$ & 8 & $8 \mathrm{~km}<\ldots<10 \mathrm{~km}$ & 8 \\
\hline$>1000$ & 10 & $>16 \mathrm{~km}$ & 10 \\
\hline \multicolumn{2}{|c|}{$\begin{array}{l}\text { Örnek: Makineye takım veya parça takma, } \\
\text { hastanede yemek dağıtma }\end{array}$} & \multicolumn{2}{|c|}{$\begin{array}{l}\text { Örnek: Konteyner yükleme - boşaltma, binada } \\
\text { yuvarlanır parçalar üstünde mobilya taşıma, çöp } \\
\text { bidonlarını boşaltma }\end{array}$} \\
\hline
\end{tabular}

Tablo 4-b. Yardımcı Araçlar

\begin{tabular}{|c|c|c|c|c|c|}
\hline \multirow{2}{*}{$\begin{array}{l}\text { Hareket Ettirilecek } \\
\text { Kütle } \\
\text { (Yuvarlanarak) }\end{array}$} & \multicolumn{5}{|c|}{ Yardımcı Araçlar } \\
\hline & $\begin{array}{l}\text { Yük Yardımcı } \\
\text { Araçsız } \\
\text { Yuvarlanıyor }\end{array}$ & $\begin{array}{l}\text { El } \\
\text { Arabası }\end{array}$ & $\begin{array}{l}\text { Tekerlekli } \\
\text { Sehpa } \\
\text { (Yönlendirme } \\
\text { Olanağı Yok) }\end{array}$ & $\begin{array}{l}\text { Transpalet, } \\
\text { Kas } \\
\text { Gücüyle } \\
\text { Çalışan } \\
\text { Forklift }\end{array}$ & Manipülatör \\
\hline$<50 \mathrm{~kg}$ & 0,5 & 0,5 & 0,5 & 0,5 & 0,5 \\
\hline $50 \mathrm{~kg}<\ldots<100 \mathrm{~kg}$ & 1 & 1 & 1 & 1 & 1 \\
\hline $100 \mathrm{~kg}<\ldots<200 \mathrm{~kg}$ & 1,5 & 2 & 2 & 1,5 & 2 \\
\hline $200 \mathrm{~kg}<\ldots<300 \mathrm{~kg}$ & 2 & 4 & 3 & 2 & 4 \\
\hline $300 \mathrm{~kg}<\ldots<400 \mathrm{~kg}$ & 3 & & 4 & 3 & \\
\hline $400 \mathrm{~kg}<\ldots<600 \mathrm{~kg}$ & 4 & & 5 & 4 & \\
\hline $600 \mathrm{~kg}<\ldots<1000 \mathrm{~kg}$ & 5 & & & 5 & \\
\hline \multicolumn{6}{|l|}{ Kaydırarak } \\
\hline$<10 \mathrm{~kg}$ & 1 & & & & \\
\hline $10 \mathrm{~kg}<\ldots<25 \mathrm{~kg}$ & 2 & & & & \\
\hline $25 \mathrm{~kg}<\ldots<50 \mathrm{~kg}$ & 4 & & & & \\
\hline$>50 \mathrm{~kg}$ & & & & & \\
\hline
\end{tabular}

Tablo 4-c. Hareket Hizı

\begin{tabular}{|l|c|c|}
\hline \multicolumn{1}{|c|}{ Konum Hassasiyeti } & \multicolumn{2}{c|}{ Hareket Hızı } \\
\cline { 2 - 3 } & $\begin{array}{c}\text { Yavaş } \\
\mathbf{0 0 , 8 m / s}\end{array}$ & $\begin{array}{c}\text { Hızlı } \\
\mathbf{0 , 8 - 1 , 3 m} / \mathbf{s}\end{array}$ \\
\hline $\begin{array}{l}\text { Önemsiz: Hareket yolu keyfidir. Yük Yuvarlanabilir veya durması bir } \\
\text { engelle sağlanır. }\end{array}$ & 1 & 2 \\
\hline Önemli: Yükün yerleştirileceği yer kesin bellidir, buna uyulmalıdır. & 2 & 4 \\
\hline Hareket yolu bellidir, uyulmalıdır. Ssk sık yön değiştirilir. & 2 & 4 \\
\hline
\end{tabular}


Tablo 4-d. Beden Konumu ve Uygulama Koșulları

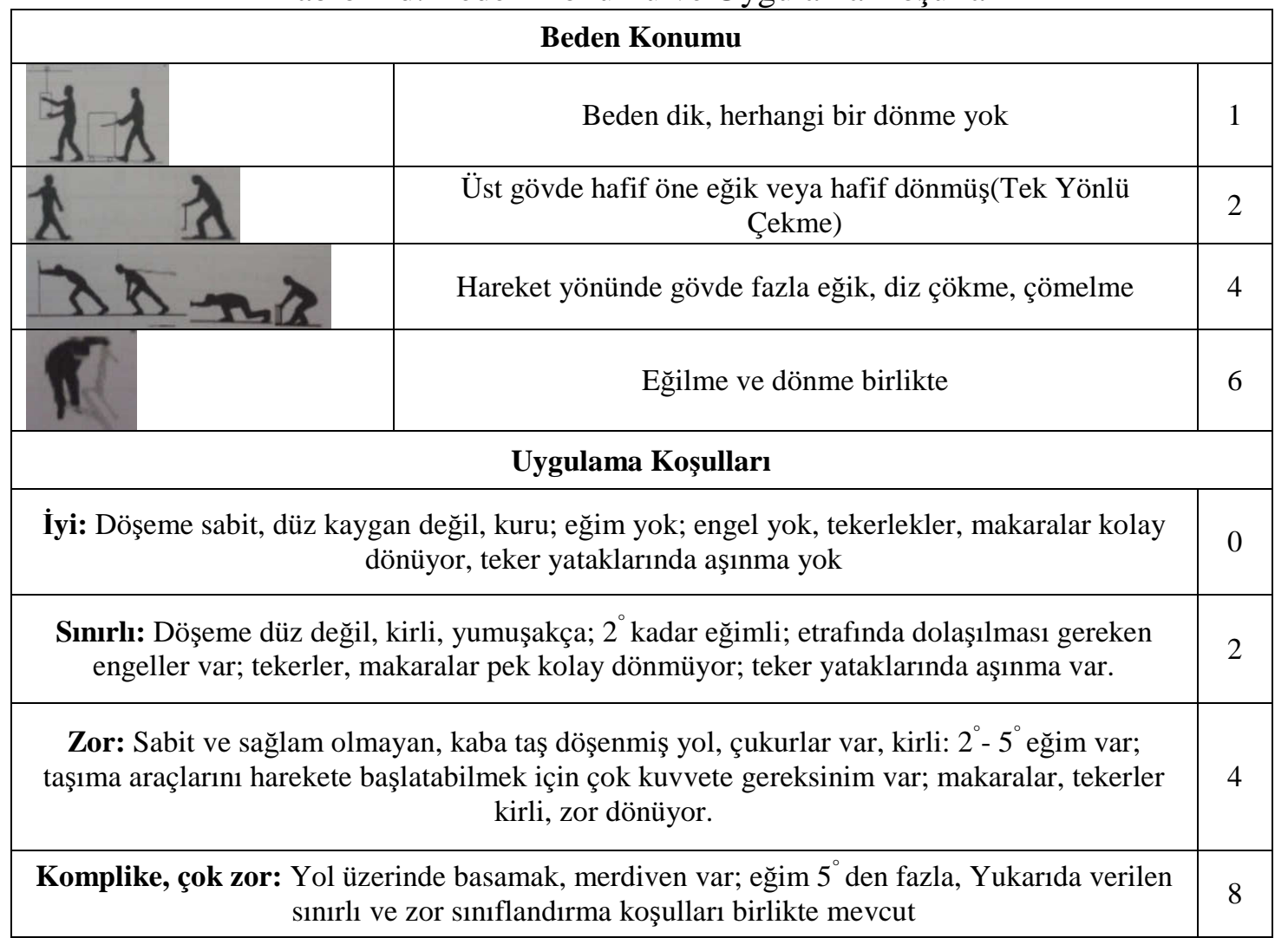

